\title{
INTEGRATION OF REVEALED KNOWLDGE INTO DESIGN THINKING: AN URBAN DESGN STUDIO EXPERIMENT
}

| Received May 24th, 2017 | Accepted January 2nd, 2018 | Available online June 15th, 2018 |

DOI http://dx. doi. org/10.18860/jia.v5i1.4202

llya Fadjar Maharika

Universitas Islam Indonesia

Yogyakarta, Indonesia

maharika@uii.ac.id

\begin{abstract}
Integration of human knowledge principle has been widespread in the world of Islamic education, including in Indonesia. Partially seen as an attempt to build a school of thought of architecture education, the principle opens the discussion on the discursive level of design thinking. This paper reveals an explorative effort to translate the idea into a class experiment in an architectural design studio. This class experimental research uses a content analysis of students' reflective writing who involve the design process that deliberately begins with the introduction of revealed knowledge (Arabic: wahy) in Architectural Design Studio 7 at the Department of Architecture, Universitas Islam Indonesia. In conclusion, it has formulated a dynamic and multi-dimensional construction of design thinking based on the integration of knowledge.
\end{abstract}

\section{KEYMORDS:}

Integration of human knowledge; design thinking; revealed knowledge; studio; urban design

\section{INTRODUCTION \\ LOCATION OF INTEGRATION OF HUMAN KNOWEDGE IN DESIGN}

As with all higher education in Indonesia, the Universitas Islam Indonesia(UII) in its effort to align the curricular policies with the Indonesian Qualification Framework (IQF) prepares curriculum concepts that must integrate attitudes, knowledge, and skills both general and specific [1][2]. In addition to demand the typical learning and evaluation methods for each of the learning outcome, this integration also provides corridors to universities at the institutional level and courses in substantial aspects to build their own particularities. In that context, the UII's development of specificity is also an attempt to show more explicitly the "school of scholarship" of education via the paradigm that has been laid out by its founders. As a university designed by the founders of the Nation, the early vision of this school of education is expressed in the introductory speech of Drs. Mohammad Hatta (as chairman of the Board of Curators and Vice President at the time) entitled "The Nature of Islamic College." In the transcript of the Opening Speech of Islamic College (or in its original name was Sekolah Tinggi Islam, as the initial name of Universitas Islam Indonesia) Hatta said that:"The Islamic College will have religion meet with knowledge in a cooperative atmosphere together, to guide society into prosperity"[3]. It appears from the transcript that the discourse of "religion meeting knowledge" meets with the integration expected by IQF. The discourse appeared even far before from the Islamization of Knowledge paradigm developed by Syed Muhammad Naquib al-Attas and Ismail al-Faruqi in the 1980s. In Malaysia, the discourse was developed through International Islamic University Malaysia (IIUM), while in Indonesia there were several attempts through State Islamic Universities (UINs). The discourse of Islamization of knowledge then developed more gently with the term 'integration of human knowledge' (IoHK) promoted by the International Institute of Islamic Thought (IIIT) and IIUM figures such as Dato 'Abdul Hamid Abu Sulayman and Kamal Hasan who tried to return to the root of an Al-Quran based paradigm [4]. For this reason, a broad assessment of epistemological and paradigmatic measures at UII has been reviewed [5].

However, this paper will not discuss the historical narrative on the loHK but open the curricular question of how knowledge integration - based on religious views - can be formulated for architecture in the aspects of design learning? The question becomes relevant mainly because the essence of architecture 
education is the design studio. The process of architectural education in various parts of the world varies greatly. However, there is one obvious similarity, which is in studio learning methods. The studio is designed as a major medium for the transfer and development of knowledge and creative exploration skills through intensive interaction between the tutor and students as well as among the students themselves. In the studio process, it is expected that students are able to generate a conceptualization of the built environment as part of a comprehensive organization of human activities. In the discourse, Salama, a professor of architectural education, believes that the design studio is the main space where students explore creative skills, and at the same time, the cradle of future architects is formed [6]. Salama also asserted that architecture is a trans-disciplinary science that prioritizes the integration of knowledge in the design process in the studio as part of its educational process. Salama illustrates that this integration is a balanced process between (a) the effort to define a goal (which is an attempt to adapt human activity to a particular type of space); (b) the effort to achieve that goal (through exploration of such space and activity) and (c) the attempts to manipulate form and space to meet human needs. Integration in the view of Salama is in the balance between the three efforts, which involves the dualism of thinking which is the task of the left and right brain: the feeling (thinking - feeling), perception and intuition (perception - intuition) and outward orientation inward orientation (extroversion - Introversion) (Figure 1) [7].

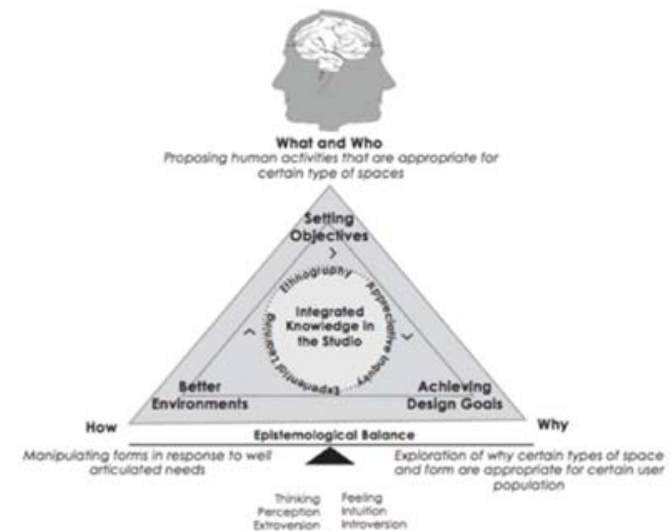

Figure 1. Epistemological balance in design in studio [7]
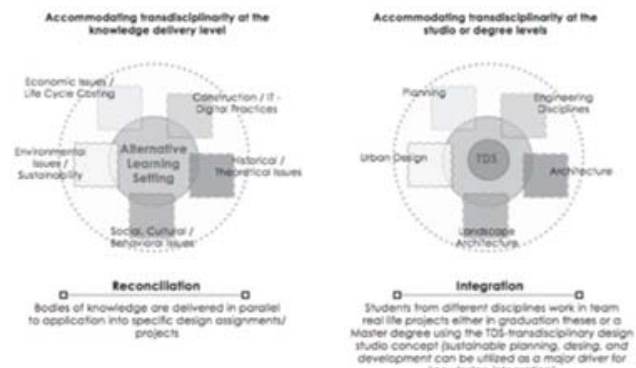

Figure 2. Integration of knowledge in the context of disciplines [7]
Salama also emphasizes the importance of integration in the context of disciplines in which the studio is a medium for reconciling various issues (environmental, social, technological, etc.) as well as integration with other disciplines (engineering, architecture, landscape architecture, urban planning, and design) (Figure 2). For Salama, the studio is a multidimensional integrative process: the integration between the scientific paradigm reflected in rational and inferential logic and the imaginative, intuitive paradigm of art. Furthermore, importantly in the studio, lecturers are challenged to change traditional pedagogy methods such as teacher-oriented classes and utilize alternative practices and encourage pioneering. Exploration of design approaches through critical debate, empirical inquiry, and varied design approaches such as community-based design, designbuild, or real studio projects are part of the opportunity of working in the studio [7].

From above curriculum direction and theoretical overview, integration of knowledge indeed becomes a shared concept. To the first concept, however, the integration of knowledge involves spiritual knowledge that expressed by divine messages or revealed knowledge,i.e., al Quran in this case. The second concept, by definition, seems not to include that realm of knowledge. This slight interpretation gap in the integration of knowledge, spiritual on one side and - say - rational on the other, opens a deeper question on whether studio design is also open to the integration of spirituality and revealed knowledge. Further, as the core of architectural education in which integration is demanded, in what role does the knowledge of revelation take part in design thinking? Thus, the question, which initially was a curricular issue, will be able to reach the epistemology of the architecture itself.

\section{ON DESIGN THINKING AS INTEGRATION OF KNOWEDGE}

In the world of architecture and urban design, the design is believed to be a complex creative skill, open but also personal. Rittel and Webber even believed that designing involves many wicked problems. Rittel and Webber define this wicked design problem as a matter of rejecting the rigor of seeking a solution because it is the result or symptom of a diverse, conflicting, and changing issue. This is very different from the tame problem, which may be very complex but allows analysis to find solutions to existing techniques (ill-defined problem). Tame design problems, on the contrary, are usually solved with a linear process over a period of time and can easily be identified when the solution is reached [8].

It is believed by designers and theorists of design thinking that design involves intuition. In the early stages of the discourse of design thinking, the design stage is considered a cognitive process, which is known as the black box. This black box cannot be defined but continues to be explored through various theories to become a process known as the glass box approach that is systematic and can be explained. John Chris Jones since 1970 defines design as an effort to 
initiate change for fabricated objects [9]. Jones saw the flashback that defines design continues to involve reconciliation between logical thinking and imagination even as early as the 1950s. Theoretical explanations continue to be done in an effort to create a more transparent design process to reduce errors. Not surprisingly, the spirit is strongly influenced by the spirit of the era that was new to computer technology (e.g., emerging programming terms used in architecture and the computer world) and industrial processes that began to implement automation controls and systems. Despite the systematic effort to make the planning process a mainstream force, other options keep the path open for the world of imagination and creative thinking, for example, with the term creative engineering [10]. Therefore, the dualism between logical thinking and intuitive, creative thinking remains an essential issue in design thinking.

The development of this systematic design discourse continues to spread and is widely adopted by many schools of design and architecture. Jane Darke, for example, proposes designing as three processes (primary generator - conjecture - analysis) very clearly giving rise to visual concept jumps before the rational explanation [11]. Peter Rowe also conceived of the discourse of design thinking as a collective consciousness in 1987 in his book Design Thinking[12]. However, throughout the discourse, various terms have been revealed that remains giving a picture of the uncertainty of how the idea of design emerged.

Newer developments in design thinking indicate intuition as an essential part. Nigel Cross assumes that designers see intuition as important and vital to the design process but require testing of the intuition in order to determine the solution [13]. For Cross, intuition is the most convenient word to describe the complex model of abductive reasoning. Abductive reasoning is a different type of reasoning from the more common inductive reasoning (reasoning from specific observation to generalization) and deductive (reasoning from general premises to specific conclusion). Nigel Cross defines abductive as a design logic that provides a way of thinking back and forth between purpose and function with the form of an object that is suitable as for the purpose and function. Cross writes it as:

"It is this particular logic of design that provides the means to shift and transfer thought between the required purpose or function of some activity and appropriate forms for an object to satisfy that purpose."[13]

Historically, drawing from Murphy et al. [14], abductive reasoning was introduced by Charles Sanders Peirce in 1955 who believed that to conclude in abduction involves a looser kind of method comparing with inductive and deductive. Since then various models continue to develop based on various perspectives and theories, ranging from design methodology to psychology, education, and others. The most contemporary role of design thinking is now even used for various fields of science that were previously alien, for example, in information technology and business. Similar to Cross's thinking, in this widening development, Dorst proposed a fundamental abductive reasoning pattern behind design [15]. Furthermore, because the creative industries are proliferating today, this design thinking has become one of the most widely used effective options and has even become a design-centric culture that emphasizes the user experience, primarily from the emotional side [16] or information technology to foster managerial commitment to new ideas [17]. In the context of effective design learning, design thinking has even become a 'buzzword' in schools. Lahey indicates, however, that the most important aspect of the design thinking is that precisely at its starting point it must free itself from the ego: "start with empathy, move ego to the side, and support students in the process of failing often and early on their way to learning"[18].

\section{EXPERIMENTON URBAN DESIGN STUDIO}

To answer the question in advance, an experiment was compiled and conducted by the author involving the students in the Architectural Designing Studio 7 (ADS). The studio is part of the effort to educate students as professional architects. Through the 2013 Curriculum, Department of Architecture, Faculty of Civil Engineering, and Planning, the Islamic University of Indonesia developed an Architecture Design Studio (ADS) from levels 1 to 7 ending with a Final Project Studio and Professional Studio 1 and 2 for Professional Education. The studio is intended as a learning medium to achieve corelearning achievement for the profession of architects, which is an ability to design that involves the process of thinking design, technical skills (think with pictures, engineering drawings, computing technology) as well as knowledge of the context and the user community of the design. Located in the 7th semester (fourth year), the ADS 7 focusing in this paper is worth eight credits, offered every academic year in odd semesters and the author in the academic year 2016/2017 became the coordinator of ten classes with a maximum of fifteen students in each class. One of the learning outcomes of the studio's learning techniques is to give the students the ability to produce a guideline for the design of the built environment especially in urban context [19].

In revealing the above questions, the author experimented with the class supervised by the author. The studio's class involve in this experiment consists of fourteen students, seven men, and seven women. As an Islamic institution, the author started by asking the students to explore and discuss the Qur'anic verses related to the city. Special attention was given to al Quran's verses related to the city such as in Surah Hijr (15:4) "And We did not destroy any city but that for it was a known decree."(QS15:4) and in Surah Hajj "And for how many a city did I prolong enjoyment while it was committing wrong. Then I seized it, and to Me is the [final] destination." (QS 22:48) [20]. Further attention also being given the nature of God such as $\mathrm{Al}$ 
Musawwir (the Fashioner of Form), which is highly relevant in the context of design.

From the discussion, it was concluded that most of the revelatory news contained in the Qur'an indicates a city narrative that usually ends with the destruction that in the Islamic theology is caused by the wrath of God. Being aware of the signs, then the students are asked to consciously do nothing - make a contemplative effort - to ask God for guidance in order to be able to design a city that can avoid doom. Only after the contemplative process is done and the students feel ready, then the studio process is run in accordance with the terms of reference work that has been prepared. This contemplative effort is meant for students to prepare inwardly and have a design intention that is theologically "right." Broadly speaking the studio lasts for fourteen weeks with three meetings per week for approximately 200 minutes. In the stages of the meetings in the studio, discussions were made that attempted to study back and forth between the Qur'anic stories and design strategies. At the end of the studio, when the design targets have been considered mature (the final draft report) the student is asked to write a self-reflection of the process that by answering four reflective questions. The questions are: (a) How does the student's response to understanding the design process relate to God's attributes, does it matter to them? (B) Are the students convinced that any inspiration or clue is believed to be the result of a reflection of a 'dialogue with God' gained during the design process? (C) How does the student feel, are they 'happy' in the process of designing of this kind? (D) Students are required to make a free comment.

Methodologically, similar activities can be performed by any students in accordance with their respective religions with the sacred texts they believe in. Thus, it is not solely in the context of Islamic belief as long as the dialog between design and spirituality can be expressed in reflective writings. In our case, the reflective writings are analyzed by the qualitative method of content analysis. Following Krippendorff [21] the content analysis was formulated according to the following criteria: (a) the data analyzed was fourteen reflective writings written by the students of the ADS 7 Class who were supervised by the author only. (B) The data is limited to textual expression and excludes verbal communication that occurs during the writing process, before or after writing. (C) The student population who participated in ADS 7 academic year 2016/2017 was 127 students who took the course for the first time and eight students who repeated the course for a total of 135 participants. The sample was only fourteen students who were members of the author's class. Thus, the sample does not provide an overview of the entire population of ADS 7 participants. The interpretation thus is limited to a specific class population. (D) From the above description of the data, context is the assignment of the author to reflect on the design process that has been done for a semester in the academic year
2016/2017. These tasks are outside the mandatory tasks directed by the term of reference, so they are voluntary and do not affect the assessment. Students understand the condition as a whole.

The analysis is limited only to attempts to draw conclusions related to knowledge integration. Information that is not related to this aspect is ignored, e.g., private comments to other students, other classes, or lecturers who do not show a connection to the issue.

\section{ON RERECTION OF CLASS EXPERIMENT}

Urban planning, especially in the era of uncertainty and contradictory expectations such as the current supermodern era is a wicked problem. At least that is what was believed by Hartmann who then required an unusual solution in an effort to manage all hope [22]. In the context of dealing with these complex and wicked problems of the city, the students are aware that in designing a city they are faced with a complexity that they have not experienced in the previous studio process. From empirical facts, they are aware that the 'fault of urban design' will result in a massive and long-term societal impact. From the knowledge of revelation brought by the Qur'an, they are increasingly aware that the city and morals are highly correlated and can have an impact on the destruction of civilization. This awareness then leads to a more optimal effort and gradually the students then work harder. The hard work seems to be carried into the realm of the subconscious. Nevertheless, from the expressions of the students, it appears that this effort is not accompanied by forced feelings, they feel able to enjoy the process because there is a responsibility and as if there are clues coming in every process that comes unexpectedly. Perhaps these unexpected solutions in design thinking are often said to be intuitive, but students interpret them more as part of the direction of God.

Fourteen students, all of whom had time to write, although grammar and accuracy of writing was not considered because it was an additional spontaneous task (in this paper, the grammar mistakes are corrected by the author for clarity and truth in scientific writing, and then translated into English, but still strive for the authenticity of the style as well as content of the writing). Some excerpts are written here that show a strong expression to each question. Responding to the question of the relationship between the designing process and the nature of God, most students were able to express the expression of the divine consciousness. They believe that designing is a manifestation of God's nature. Ardan, for example, wrote as follows:

"Actually, every existing form, those which have been lost, and those which will be created are already there, prepared by God. When a creator, whether it is artists, designers, architects, and the like says 'I created this work' I feel from my perspective, the statement is not quite right. From my point of view, all the designers only find a form from which Allah has created which is then realized in the human 
dimension. Designers are the transmitter of the form God has prepared in the world." (Ardan Muhammad Pratito, translated from Bahasa Indonesia).

Lisa writes more emphatically: "Understanding the design of the properties of Allah SWT, in my opinion, is the most correct. I say so because what happens when we design without any foundation from Al-Musawwir, ultimately makes the design a medium to vent the egos of a human being that may ultimately be destructive."(Lisa Tri Nopyanti, translated from Bahasa Indonesia).

Although vaguely Safira also indicated the same:"I feel God has a compulsory nature that we can know and that can be implemented into a real form created through the intermediary of man/architect/ designer of his will." (Safira Salsabila, translated from Bahasa Indonesia).

Responding to the question of the connection between divinity and theme, all students are able to formulate a link between the two. Abdullah Chilmi writes one of them: "In designing the Seturan region which in fact is a region with a high level of criminality [1] applied the concept of Crime Prevention Through Environmental Design to suppress the crime rate itself. Here I am trying to position myself as a designer who applies Allah's instructions with the nature of al Mu'min (Allowing security), which He has through the design of this Seturan region." (A. Chilmi, translated from Bahasa Indonesia).

Similarly, there are attempts to use divinity as a 'design process' as Fadhli's formulation follows:"Allah Almighty has 3 names namely Al-Khaliq (Creator), AlBari (Producer), Al-Musawwir (Fashioner of Form). In designing the area based on the 3 names of God, done by first imagining/reconstructing existing thoughts for humans can be obtained through surveys and data collection of the area and the behavior of the population. By linking existing data, we can determine a work in which the quality depends on the creativity of each individual, then start development according to the planning systematically."(Fadhli, translated from Bahasa Indonesia).

Alternatively, it involves God in all efforts associated with the Studio, as Dwi Rosida believes. She writes:"Usually every idea I get I will ask myself again is this good if I am the one who feels this design? Does this design give many possibilities to do good? This is the kind of question I am unconsciously thinking throughout the day during work on ADS and other activities. During this design studio, I became accustomed to adding prayers for this studio. [This habit] was done after following a session of the studio discussing the understanding that what we are doing should continue to involve God Almighty in everything. It makes easy for me to work on this ADS, show me an idea that leads to goodness, and strengthens my heart to keep up the strength to continue working on ADS."(Dwi Rosida, translated from Bahasa Indonesia).

Responding to the second question as to whether there is any inspiration or clue that is believed to be the result of the reflection effort gained during the design process. All students indicated that during the design process there were "unexpected creative jumps" or felt there was out of the box thinking. They agreed that even if they were not 'forced' by their lecturer, they felt there was a subconscious mind that encouraged to them to always think about the challenges of the problems and solutions that arose from ADS 7. Some students even revealed ADS 7 often showed up in their dreams. Thus, solutions emerged at times they did not expect. Amira for example accurately reveals this indication: "Yes, often there were jumps in problem solving even when not thinking about ADS (the subconscious mind itself was embedded to always think of ADS"(Amira Rasyida Sarah, translated from Bahasa Indonesia). Gustavian express his feeling also:

"In addition to looking for existing data I also felt closer to God to be able to get inspiration in the design (black box). I feel In the process of designing, I often got surprises. As if directed. For example, when doing a site survey for $\operatorname{ADS} 7$, which at first, I just wanted to do for the documentation, suddenly citizens came to talk about the site. They told me things that happened on the site and even the problems in the area. And there were other surprising things."(Gustavian Dewantara, translated from Bahasa Indonesia).Fauzan illustrates the opening of dialectics between "normal" design and design with the nature of God that demands unconventional understanding. Fauzan writes:

"The habit of understanding design for an architect or student is common to understand with other people, but for a human being to understand the design with the qualities of God requires an out of the box understanding because it deals indirectly with the Almighty."(Fauzan Meidhy Akbar translated from Bahasa Indonesia).

Lisa, on the other hand, was not very sure but she tried to enjoy and simultaneously hone sensitivity to various things during the design process. She also felt happy with the design process that involved understanding divine nature and then feeling confident in the choices of solutions she thought of. Lisa writes:"Inspiration when it came I was not able to clearly explain what could even be called 'inspiration' and what was not. What is clear, again I always try to enjoy every process, and I always try to hone my sensitivity to things like that. One thing is clear, until now the process of designing that from the beginning has been using the foundation of Al-Musawwir makes me happier in running it because I always wait for it piece by piece, setting by setting, on the journey there will always be something new (I'm pretty sure that includes inspiration sir?) (Lisa Tri Nopyanti, translated from Bahasa Indonesia).

Viyata expressed a slightly different view about the essence of Islam. She wanted to attempt to be more sensitive because she designed a market in the Christian city of Manokwari. Viyata reveals: "To make it happen in a design is often to relate it to the buying and selling system advocated by Muslims, but seen 
again in terms of the background of the area which is the city of the gospel with a majority Christian community, to apply it felt a little difficult. What is then done is making the region seem to impose the Islamic trading system without changing the character of the city. " (Viyata, translated from Bahasa Indonesia).

Responding to the question of the involvement of feelings in the process of designing all students agreed that they were happier and more comfortable than when the studio was just "following the term of reference." Some expressed it by thematically linking. Wuri who designed a water conservation area on the slopes of Merapi gives an example:"The pleasure I feel in this design process is that I learned to design by learning life. I learned about the philosophy of water through an article, where does water always fill the existing space, by following each of these design processes, maximizing on them, there will be new and exciting things in each process. Where indeed results never lie for business and God Almighty as a planner.

The above was a pleasure in the process of designing in ADS 7. (Wuri Hamumpuni, translated from Bahasa Indonesia).In addition to showing pleasure, Dwi Rosida also emphasized the existence of the dualism of reference that is the reason and the guidance of God:"I love this studio running with every one of us trying to do good in their respective region, as well as practicing courage to take decisions on the basis of our consideration as human beings with the intellect and the demand for guidance to God."(Dwi Rosida, translated from Bahasa Indonesia).

Responding to the request to give free commentary on the Studio process, the students pointed out the variations. Annisya felt StuPA 7 was impressive because it was 'different' and meaningful. Annisya reveals:"Every stage of the studio mentions designing based on the Qur'an. But the most memorable design based on God's knowledge is ADS 5 and ADS 7. There is a difference to other studio processes because designing on the basis of God's nature in these two studios is like feeling a deeper meaning, understanding that designing is not merely aimed at generating image sheets designed for specified functions and systems."(Annisya Tamara, translated from Bahasa Indonesia).

Some students have optimism that they can design even better. Nizar expresses it as follows:"Designing is a form of reward because of its implications for the many things around it. We continue to be diligent in developing ourselves in order to produce a better design product from previous designers. Because basically we also evolve over time. (Nizar Caraka, translated from Bahasa Indonesia). Some students feel they have a bigger responsibility and are grateful to learn architecture as a science. Chilmi and Wuri write the following:

"... Feeling [that we] have a huge responsibility of knowing that anything that we design can affect (even the effect can be very significant) on the behavior of people who are in the area where we design...." (A. Chilmi, translated from Bahasa
Indonesia). While Wuri writes:"The feeling I have in my current position and being in this class is that I am grateful to Allah SWT because I am given the opportunity to learn about the science of architecture that I really want to learn, I am given the opportunity to meet great people who broaden my horizons, and I am given the sciences that I need to develop and how to be broad-minded." (Wuri Hamumpuni, translated from Bahasa Indonesia).

Different experiences were presented by Alif who felt not altogether happy with the approach at first but then benefited:"It never occurred to me that I would go into the open design approach in ADS 7, it is again because of my idealistic mindset that is constrained when thinking with open patterns. However, I was grateful to get into this study group, because it can improve my mindset to be broader, see many more aspects, even aspects that are very small, as possibilities. Here I learned to be an open-minded person, and it's fun because I can see things from many perspectives. This learning is very valuable to me, and I will develop a pattern like this into an idealistic mindset of "open mind idealism" (Alif Angga Risky, translated from Bahasa Indonesia).

\section{DESIGNING AS AN INTIEGRATION PROCESSOF KNOWEDGE AND REVELATION}

In the back and forth between purpose and form, Salama indicates the need for knowledge integration within the trans-disciplinary context and a balance between left and right brain, between thinking -feeling, perception and intuition, And outward orientation - self-orientation (extroversion introversion). However, in the context of knowledge integration with knowledge of revelation or the divine message and spirituality then the integration dimension will increase. In the course of alternating between thoughts and feelings, between the left and right brain, between purpose and form a pause allows the relationship with the divine knowledge to be built. The students have directly indicated it, and they feel 'comfortable' with the shocks experienced.

Trying to use the Dorst framework, it appears that the design process is fundamentally different from its frame of induction - deduction reasoning. Both of these reasoning processes are only suitable for helping in predicting and explaining the phenomena of the world but not enough to offer a new value inherent in the design. In line with Cross, Dorst also agrees that there needs to be a new framework in reasoning that aligns with abduction reasoning. Nevertheless, Dorst further induces this abduction reason with Abduction 1 and Abduction 2. Abduction 1 is described by the following equation [15]. Abductive 1 is described as an equation in the following (Figure 3 ).

This reason illustrates that when a person designs a city (WHAT) and has knowledge of the theories (HOW) then hopefully a good city will be realized (VALUE). This equation is similar to common problem solving, but in many ways, the equation is incomplete. For example, when one of its elements does not exist, the equation becomes open. 


$\underset{\text { Thing }}{\text { WHAT }}+\underset{\text { Working Principle }}{\text { HOW }} \rightarrow \underset{\text { Aspired }}{\text { VALUE }}$

$\underset{\text { City }}{\text { WHAT }}+\underset{\text { Urban Design }}{\text { HOW }} \rightarrow \underset{\text { "Good City" }}{\text { VALUE }}$

Figure 3. Framework of Abductive Reasoning, modified from [15]

The design problem becomes open when the two elements of WHAT and HOW are absent, and only the VALUE element is known. This is where the design becomes different from traditional problem solving and becomes Abduction type 1 because the designer in parallel thinking needs to set up the framework (FRAME). Subsequent developments are illustrated by the following equation which gives rise to the reasoning of Abduction type 2: (modification of Dorst 2011) (Figure 4):

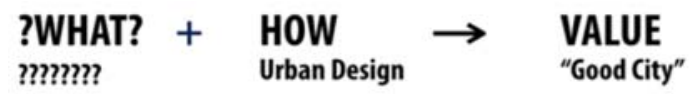

$\underset{\text { City }}{\text { WHAT }}+\underset{\substack{? \text { ?HOW?? } \\ \text { ?m? }}}{\rightarrow} \quad \underset{\text { VALUE City" }}{\text { VALUE }}$

Figure 4. Framework of Abductive 2, modification from [15]

This is the reasoning of Abductive 2 with design dimension. In this equation, designing a city that makes the inhabitants have a good personality (? WHAT?) is still speculative, and its principles (?HOW?) are not well-formulated either. However, the designer knows exactly that there is hope to shape a city that will bring benefit and avoid the wrath of Allah (VALUE). This is where the role of revealed knowledge becomes instrumental because it opens up a possibility of giving a framework (FRAME) on the design reasoning. A frame according to Dorst, is a linking between certain things, certain working principle leading to attainment specific value [15]. In our experiment, student reflection has presented thoughts and awareness to the FRAME so that speculation both from the WHAT side and from the HOW side open up. Moreover, these speculations become so important in the formation of the framework, because the designer will often deal with paradoxes. This framework does provide the possibility and response to a paradox by raising the theme. For Dorst, these frameworks and themes will be of great help to other disciplines as well as within organizations in responding to complex problems.

Seeing from those equations, our experiment shows that the introduction of God's message on cities has changed the students' awareness of urban design, not just looking for the value, knowledge, and skills of city design (WHAT and HOW) in theoretical manner where all seemingly clear (Figure 3) but push to more complex nature of the city (Figure 4). The introduction of revealed knowledge that the cities may receive the wrath of Allah has changed the students' intention, not only pursuing the good design of the city but also intending it to be a God's blessed city that is beyond the design objectives (Figure 5). The revealed knowledge and design intention play as a new frame for students in attaining the specific characteristic of the intended city.

From a curriculum point of view, the design intention and process observed in the experiment also reached beyond its learning outcome. Considered by many students as part of their worship, the studio stimulates peace of mind and at the same time hard work and determination in their effort to complete the studio tasks.

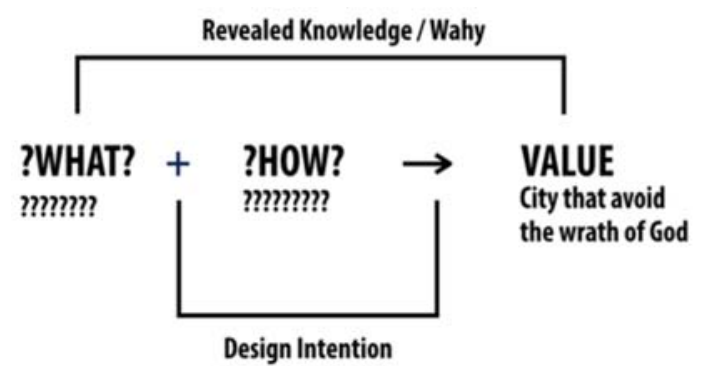

Figure 5. New framework of design thinking based on the integration of knowledge and revealed knowledge as FRAME [Source: author]

Intention and dialogue with the knowledge of revelation (the Quran in this case) open the way for the emergence of critical discourse that designing is "only found the form from which Allah has created which is then realized in the human dimension" as Ardan writes. This expression is inline to Lahey's indication that to design is to start with empathy and put aside the ego in design thinking [18].

Indeed, the latest development of this design thinking is the existence of a critical point that even some experts think to abandon the term. However, in the learning process for the students of design (architecture for example), practicing design by giving the big picture of reasoning as above is still very meaningful. Perhaps a model with dynamic and multidimensional abductive reasoning (with revelatory knowledge and spiritual/intentional) should become the new model (Abductive 3) to be considered in the learning process of design as well as design thinking. The expression of the students in understanding the process of designing and positioning the knowledge of revelation within their frame of mind integratively and even partially to influence behavior - gives meaning apart from giving color and the theme of FRAME also gives 'pleasure' in the process of designing itself. When the new generation of designers are able to put sincere intention into designing by not just expressing the ego, but with the joy of exploring and opening up to inspiration in addition to enriching the normative designer's principles there is hope of the emergence of a design that provides an alternative route of urban development that is authentic. 
Our intention is not to prove or disprove the experiment with Supreme Being as prima causa of the design. Rather, to push forward the level of integration of the studio culture. The author believes that how the state of spirituality experienced by the student may lead to a state of mind fertile for new ideas. It is integration not only in term of the right-left side of the brain but also brain and soul. Indeed, such a state of mind, may invite us to more discourse and questions including serendipity as well as neuroscience. Serendipity is defined as a stance of "accidental information discovery" [23]. Serendipity has started to be one of the factors or situations that create nove discovery including in chemistry or digital design. Liang (2012) sees that serendipity is the phenomenon of spontaneously understanding unexpected things [24]. More question may be risen including do student's experience can be associated with the state of serendipity? Do pleasure create a situation that serendipity may occur? Is serendipity may be the prima causa of the design?

Another venue for discussion is on neuroscience. By the analysis of cognitive activity data of the brain using Electroencephalogram (EEG) the work of Yuan et al. proves that knowledge connection acts as the core in the thinking process of idea generation. They believe that stimulus information has certain kind of connection with the levels of brain activation [25]. From this finding, more question may also be risen such as in what studio environment do best design may be achieved? In what area of the brain is good design achieved? Can we enhance design ability through information stimulus to increase brain activities in achieving good design? Indeed, these two discourses are outside the venue of discussion in this paper. However, through this small experiment, it opens up the necessity of more research and experiment in design thinking and design learning as fundamental part of architectural education.

\section{CONCLUSION}

Of course, a little experimentation conducted by the author still needs further exploration to be able to reveal the secrets of integrated design process whose dimension is on the submission to the guidance of revelation in addition to the efforts to develop logical reasoning. Nevertheless, the above exploration is expected to help lecturers and students to make the design process more explicit and put the integration of divine knowledge in the right proportions. Lecturers and students can still see design thinking as a multidimensional, dynamic process that involves both logical and creative processes but also gives intuitionand inspiration-the proportion that is still conscious as part of the process. The experimental research of this class also indicates that the reflective process through the formation of a large framework (FRAME) involving the element of spirituality should not be taboo in design. The author calls this framework as Abductive 3 . Through this framework, the author believes that the designers will gain strength when the design process is very closely accompanied by spiritual exercises to produce unexpected results.

Despite the limitations of samples and content analysis of this qualitative nature, this experiment opens new doors that the exploration of design thinking should most likely explore by the neuroscience approach of seeing the brain's chemical response in receiving the impulse of revelation knowledge. Exploration can also be done in the realm of the main design by visual analysis to assess, for example, the application of design processes based on different levels of expertise such as beginner to experts to designer visionaries or the generic stages as indicated by van Dooren et al. [26]. The area of research will provide an opportunity for the design to be more explicit so it can be taught and studied easily.

\section{ACKNOWEDGMENT}

Sincerest thanks to Nizar Caraka Trihanasia, Viyata Maryana Wardani Makatita, Ardan Muhammad Pratito, Fauzan Meidhy Akbar, Safira Salsabila, Fadhli, Amira Rasyida Sarah, Lisa Tri Nopyanti, Abdulloh Chilmi, Annisya Tamara E, Dwi Rosida, Alif Angga Risky, Wuri Hamumpuni, and Gustafian Dewantara who had finished this Architectural Design Studio 7 very seriously. The funding for this experiment was partially supported by the Department of Architecture, Universitas Islam Indonesia.

\section{REFERENCES}

[1] Presidential Regulation No. 8 of 2012 concerning Indonesia Qualification Framework (Peraturan Presiden RI Nomor 8 Tahun 2012 tentang Kerangka Kualifikasi Nasional Indonesia, KKNI).

[2] Regulation of Minister of Education and Culture No. 73 of 2014 concerning the Application of IQF in Higher Education (Permendikbud Nomor 73 Tahun 2014 tentang Penerapan KKNI Bidang Pendidikan Tinggi).

[3] Universitas Islam Indonesia, 72nd Anniversary of Universitas Islam Indonesia (translated from 9 Windu Universitas Islam Indonesia. Yogyakarta: UII Press, 2015.

[4] K. Hassan, A Return to the Qur'anic Paradigm of Development and Integrated Knowledge: The Ulil Albab Model, (2), 183-210, 2010.

[5] N. Kholis, I.F. Maharika \& F. Wahid, "Recasting the Disciplines Under the Framework of Islam: Lessons from the Textbook Writing Initiative at Universitas Islam Indonesia," Proceedings of the International Conference in the Integration of Contemporary and Islamic Knowledge in Islamic Universities, Gontor, Indonesia, 12-14 December, 2015.

[6] A. M. Salama, (Ed.) “Design Studio Teaching 
Practices: Between Traditional, Revolutionary, and Virtual models," Open House International, 31(3), pp. 1-116, 2006.

[7] A. M. Salama, "A Theory for Integrating Knowledge in Architectural Design Education," Archnet-IJAR, International Journal of Architectural Research, Vol 2, Issue 1, March, 2008.

[8] H. W. Rittel \& M. A. Webber, "Dilemmas in a General Theory of Planning," Policy Sciences, 4, pp. 155-169, 1973.

[9] J. C. Jones, Design methods. NY: John Wiley \& Sons, 1992.

[10] J. C. Jones, "A Method of Systematic Design" in Cross N. (ed) Development in Design Methodology, NY: John Wiley \& Sons, pp. 9-32, 1984.

[11] J. Darke, "The Primary Generator and the Design Process," Design Studies, Volume 1, Issue 1, pp. 36-44, ISSN 0142-694X, http:// dx.doi.org/10.1016/0142-694X(79)90027-9 (http://www.sciencedirect.com/science/article/ pii/0142694X79900279) 1979.

[12] P. Rowe, Design Thinking. Cambridge MA: MIT Press, 1987.

[13] N. Cross, Design Thinking, Understanding How Designer Think, Oxford, New York, Berg, 2011.

[14] K. M. Murphy, J. Ivarsson, \& G. Lymer, (2012). "Embodied Reasoning in Architectural Critique", Design Studies, 33(6), 530-556. https://doi.org/10.1016/j.destud.2012.06.005.

[15] K. Dorst, "The Core of 'Design Thinking' and Its Application”, Design Studies, 32, 2011, doi:10.1016/j.destud.2011.07.006.

[16] J. Kolko, "Design Thinking Comes of Age," Harvard Business Review, 2015, [retrieved from https://hbr.org/2015/09/design-thinking-comesof-age, 2017-01-05].

[17] R. L. Martin, "Use Design Thinking to Build Commitment to a New Idea," Harvard Business
Review, 2017 [retrieved from https:/ hbr.org/2017/01/use-design-thinking-to-buildcommitment-to-a-new-idea,2017-01-05].

[18] J. Lahey "How Design Thinking Became a Buzzword at School", The Atlantic, 2017 [retrieved from https://www.theatlantic.com/ education/archive/2017/01/how-design-thinkingbecame-a-buzzword-at-school/512150, 2017-0105].

[19] Term of Reference, Architectural Design Studio 7, 2016 [in Bahasa Indonesia].

[20] Al Quran retrieved from https://quran.com

[21] K. Krippendorff, Content Analysis: An Introduction to Its Methodology (2nd ed.). Thousand Oaks, CA: Sage. p. 413. ISBN 9780761915454, 2004.

[22] T. Hartmann, "Wicked Problems and Clumsy Solutions: Planning as Expectation Management," Planning Theory, 11(3), pp. 242256, 2012.

[23] R. M. Roberts, "Serendipity: Accidental Discoveries in Science," Serendipity: Accidental Discoveries in Science, by Royston M. Roberts, Pp. 288. ISBN 0-471-60203-5. Wiley-VCH, June 1989., 288, 1989.

[24] R. H. Liang, "Designing for Unexpected Encounters with Digital Products: Case studies of Serendipity as Felt Experience," International Journal of Design, 6(1), 41-58, 2012.

[25] P. Yuan, Y. Xiong, Y. Li, L. Liu, \& M. Li, (2017). "An Exploration into the Influence of Stimulation Distance of Stimulus Information on Design Thinking Based on EEG Alpha Activity", Jixie Gongcheng Xuebao/Journal of Mechanical Engineering, 53(15), 40-48. 2017 doi:10.3901/JME.2017.15.040.

[26] E. van Dooren, E. Boshuizen, J. van Merriënboer. "Making Explicit in Design Education: Generic Elements in the Design Process," International Journalof Technology and Design Education, 24: 53. doi:10.1007/ s10798-013-9246-8, 2014. 